\title{
Young adults and the digital public sphere: a cross-cultural perspective
}

\author{
Micheline Frenette, Marie-France Vermette \\ micheline.frenette@umontreal.ca \\ 'University of Montreal, ${ }^{2}$ University of Ottawa
}

\begin{abstract}
This paper deals with the engagement of young adults in the digital public sphere and attempts to identify some important issues related to the phenomenon as well as some of the challenges for future research. It has often been asserted that the newer generations are disenchanted with traditional party politics and prefer alternative forms of political engagement. Concurrently, it has been stated that, because of their pervasive involvement with ICTs and the unique opportunities they offer, the digital public sphere has become a place of choice for them to enact these newer forms of political engagement. The hypothesis that young adults are part of a digital generation that has redefined its modes of functioning within society has been a motivating factor for a study conducted among university students in four different countriesi to see how these new practices play out in the various spheres of their lives. Among other issues, we explore to what extent and in what ways the Internet has become a new vector for political participation among young adults. We will use part of these data to support our reflection on young adults' involvement in the digital public sphere and to re-examine the classical premises of what constitutes the public sphere. We conclude by sharing our insights on this phenomenon and discussing further avenues for research in this area.
\end{abstract}

KEYWORDS

Digital public sphere, political engagement, young adults, ICTs

\section{INTRODUCTION}

Young people's involvement in political life is a crucial issue for democratic societies around the world. Indeed, young adults' disengagement with traditional party politics as expressed in voter turnout has been widely documented these past years. The turnout of youth (18-24 years old) at the American presidential elections has steadily gone down over the past forty years (Mindich, 2005: 22) from 50,9 per cent in 1964 to 32,3 per cent in 2000. A similar pattern was found in Quebec (Canada) by Bélanger and Nadeau (2009) and Blais (2008). However, this trend is not specifically North American: similar developments are found in Western Europe, Japan and Latin America (Niemi and Weisberg, 2001). For example, in France, there has been a decrease in traditional political participation (voting, campaigning for a party) and an increase in participation through protests (strikes, petitions, demonstrations, etc.) (Galland, 2009). In fact, Loncle (2007) reveals that $85 \%$ of French youth do not want to be associated with a political party while only $30 \%$ of them would be reluctant to participate in a demonstration or a strike. In

\footnotetext{
"The other researchers on this project are: Pascal Plantard, Université de Rennes 2, France; Julieta Espinosa, Cony Saenger y Pedrero, Elisa Lugo Villaseñor and Maria Teresa Yurén, Universidad Autonoma del Estado de Morelos, Mexico; Ulrika Sjöberg, Halmstad University and Ebba Helena Sundin, Jönköping University, Sweden.
} 
Mexico, a recent survey of youth values reveals that $43 \%$ of them are not interested in politics, and $46 \%$ only a little (Imjuve and UNA, 2012).

Overall then, young adults appear to have less knowledge of and less interest in traditional politics, while they are said to be, instead, more likely to participate in new forms of political engagement to make their voices heard. The Internet and other information and communication technologies (ICTs) have been hailed as instrumental in supporting these new forms of engagement in public life. In fact, observers have taken some comfort in the fact that most young people, especially those with high levels of education, are presumed to be actively engaged in the digital public sphere. Farthing (2010: 181) argues this line of thought when he states: "Young people's relationship with contemporary politics is complex. They are often chastised as the apolitical harbingers of an incipient 'crisis of democracy' while simultaneously heralded as the authors of sophisticated new forms of politics, most notably within electronic realms".

A major consequence of these social transformations is to lead us to rethink our definition of political involvement. In fact, for Farthing (2010: 185), disengaging from traditional politics can be construed as a sign of opposition against a type of politics that is perceived as not doing enough for the welfare of citizens and could be considered as "a legitimate response to faulty institutions themselves". Beck (2001: 159) goes as far as to state that rejection of traditional politics is "a powerful new form of action". We are thus led to conclude that young adults are not apolitical but that it is the very substance of their political agenda as well as its spheres and forms that have changed (Furlong and Cartmel, 2007; Bennett, 2008). In the same line of thought, Miegel and Olsson (2012: 490) advance the hypothesis that the Internet "has interplayed with young people's forms of life in a way that has given rise to new social and cultural issues with a destabilizing effect on the adequacy of established social and cultural norms and values". Finally, Farthing (2010: 188) is of the same opinion, as he states: “... today's young people are not the problem; rather young people's rejection of politics is their way of negotiating the new freedoms of a risk society".

Our purpose in this paper is to contribute to the ongoing reflection on these issues by drawing on data from an international survey among college students. We will first review some of the literature that seeks to understand young people's disengagement from traditional politics, in what ways ICTs offer new possibilities for citizen participation, and why the latter are especially appealing to young adults. We will then present data from our study on young people's Internet practices related to politics. In doing so, we will discover that these practices are not as homogeneous or as enthusiastic as much of the literature suggests and that cultural differences are apparent. Subsequently, we will attempt to understand the significance of these results in the light of classical notions of the public sphere and conversely, reflect on the relevance of these concepts to help us grasp the reality of the digital public sphere. 


\section{FROM TRADITIONAL POLITICS TO ALTERNATIVE FORMS OF ENGAGEMENT}

In what ways can ICTs be said to transform the rules of political engagement in a general manner? According to many sociologists such as Wolton (2008), even though communication media are not without their paradoxes, they remains the functional and normative condition for debates in the public space. Indeed, media have always served as an important relay of information between those holding power and the general population, but for a long time, the communication was mainly unidirectional. Their recent transformations (i.e., immediate access to information, variety of sources from all over the world, possibility for the public to intervene, and so forth) inevitably have consequences for how power relations play out, both within and between the public spheres. Thus, Miège (2010: 116, our translation) makes a case for the central role of media in the contemporary public spheres: “... the themes that are debated, the fragmentation of partial spaces and the different categories of exchanges among participants are, one way or another, in relation to the media system, although the latter has been made more complex doubly: on one hand because of the multiplication of the organizations that compose it, on the other hand because of the mutual and crossed relationships between media and even with the hors-media [public relations, communication agencies]". Dahlgren $(2008,2012)$ also underscores the importance of taking into account the new role played by media in the public spheres by stating that the latter are contributing to the fall of the public sphere long deemed universal and rational. For Dahlgren, the public sphere is becoming a "sphere of representations" where the market rationality prevails and common interpretative frames are created among sub-groups of the population.

It would appear then that the Internet is truly contributing to a reconfiguration of the public sphere. For some authors (Dahlgren, 2008; Wolton, 2008; Miège, 2010), this mutation of the public sphere is occurring at a faster pace, now that the majority of citizens in Western countries have access to and use the Internet on a regular basis. For Cardon (2010: 10-11, our translation), this digital public sphere is "transfused by two new dynamics that permit the enlargement of the traditional public sphere: the privileged access of professionals to publication has been taken away leading to an outbreak of amateurs that broaden the perimeter of democratic debate while the aspirations of personal expression of Internet users create cross-over sensibilities between private sociability and public debates". Indeed, the possibility to speak up in public is expanded to society at large while private conversations are now gaining public visibility. With ICTs, boundaries between the public and the private are blurry and social spaces and media have become entangled.

The Internet has an impact on how power relationships play out in society because, among other factors, it enlarges the possibility of participation by allowing forms of expressions that are less demanding, socially and culturally speaking, as well as being very appealing. For instance, the interactive features allowing us to receive personalized feedback and the capacity to interact instantaneously with other parties, are characteristics of ICTs that facilitate participation. Moreover, ICTs allow engagement in the public sphere in terms of what Caron and Caronia (2005) call the non-temps and non-lieu, meaning that 
you can participate in the public sphere, at any time and from anywhere. ICTs allow for a composite of micro-spaces of debates that are relentlessly constituted, dismissed or displaced through both traditional and new modes of expressions, ironic or dissenting, that are developed at the margin and at a certain distance from official politics (Cardon, 2010: 70-72). Actually, media such as the Internet facilitate debates among citizens as well as communication between them and politicians. Indeed, debates in regard to expertise most often oppose citizens to official institutions, the former not wanting to defer to the latter.

In spite of these encouraging developments, we should not conclude that power relations in the digital public sphere are totally evacuated because, as Cardon (2010) says, there is a difference between access and visibility online. In addition, the existence of these numerous micro-spaces, despite the diverse advantages they offer, does not mean that all citizens are politically engaged, on the contrary. Behind this democratic horizon of the "all-participative" according to Cardon, (2010: 80), is unfortunately reproduced the unequal distribution of sociocultural capitals. However, previous research leads us to belive that our population of interest, university students, is one of the sub-groups most likely to avail itself of the possibilities of participation in the digital public sphere. We will now turn our attention specifically to this topic.

\section{Young ADULTS' ENGAGEMENT IN THE DigitAL PUBLIC SPHERE}

\subsection{DefinitiVe NEW POSSIBILITIES}

Taken altogether, these characteristics of ICTs that enable new forms of engagement in the digital sphere seem to be especially appealing to young adults. But what is it precisely about the digital public sphere that supposedly encourages young adults to adhere to these alternate forms of political participation? In fact, "[...] a pervasive assumption exists that new communication technologies, that tend to be adopted by younger members of society quickly, might bring more youth into the political process" (Stromer-Galley and Wichowski, 2011: 174-75). Authors such as Livingstone et al. (2004) and Vromen (2007) agree that, once we expand our understanding of political participation, we are led to conclude that young people do participate politically online in new ways. Indeed, "ICTs provide the capacity not only to forge new political communities of young people, but also to inform other, alternative political forms from 'boycott Nike groups' on Facebook to email forwards about the ethics of rainforest agriculture" (Farthing, 2010: 186).

McKee (2005: 74) adds: "Traditional forms of politics are not mobilizing youth activists the way the anti-globalization movement is" and explains it by the fact that young adults prefer social movements where conversations (rather than authoritarian relationships) are an inherent part of the political process; they move from traditional politics to what he calls cultural politics. For Farthing (2010), the political agenda of young citizens has two key features: they transcend national borders (i.e., engaging with world-wide non governmental organizations, signing an international petition for the safeguarding 
of the environment, etc.) and actions undertaken are on a smaller scale, more intense and personalized. Some authors (Giddens, 1991; Beck, 1992; Furlong and Cartmel, 2007) have suggested that "many have turned to a new form of political participation: the "life politics' of self-actualization, or living your political ideology. This leads to what has been described as 'micro-political' actions (Pattie et al., 2004) or 'cause-oriented' actions (Norris, 2003), in which young people's actions are not directed towards the state but rather towards specific issues" (in Farthing, 2010: 188-9). Finally, Theocharis (2011: 219) describes what he calls "postmodern politics" as a "younger movement that celebrates the possibility of ironic, humorous and contradictory political actions'.

\subsection{DiffERENCES AMONG YOUNG ADULTS}

Even if traditional politics is undergoing significant transformations and cultural politics is blossoming, it does not mean that all young adults engage in one or the other of the aforementioned types of politics facilitated by ICTs. Indeed, some authors (Stockemer, 2010; Bastien, 2004; Sarra-Bournet, 2008) argue that sociocultural backgrounds heavily impact political participation, education being one of the prime variables. Indeed, Bélanger and Nadeau (2009) claim that young adults with a college diploma participate more that the ones with a high school diploma because education influences political consciousness and feelings of civic responsibility and personal efficiency. Many other psychosocial factors are also positively linked to political engagement, such as: attitudes toward the political system (Pammett and Leduc, 2005), political knowledge (Bastien, 2004; Milner, 2007) media consumption (Sarra-Bournet, 2008), membership in a social organization (Britt, 2003; Wells and Dudash, 2007) and the desire to express one's point of view (Blais, 2008).

However, since a higher level of education is constantly associated with political engagement, we have centered our attention on university students. They represent a segment of the population in which Internet uses are usually more intense and versatile and, as a consequence, they are more likely to exemplify the emergence of new communication practices (Bennett, 2008). This has been confirmed by studies showing that young adults who have better opportunities for education and who are studying in a college are more prone to engage in the public sphere and more likely to have a wider range of practices (Theocharis, 2001; Farthing, 2010). Finally, some studies on the concept of "emerging adulthood" (first proposed by Arnett, 2004), have come to the conclusion that students from different social backgrounds have in common a contemporary culture and life habits that transcend national borders and that are reflected in their appropriation of digital technologies. One of our working hypotheses was to verify to what extent students from different cultures are indeed more similar than different with regard to their political practices online. 


\section{A COMPARATIVE INTERNATIONAL SURVEY}

We conducted an international survey among university students in four different societies, Canada (Quebec), France (Brittany), Mexico and Sweden, to explore to what extent they are involved in the digital public sphere and if so, how similar or different they are in that respect. The countries participating in the study are quite dissimilar culturally and politically speaking and in terms of language spoken and historical roots. In other words, one of our goals was to observe whether or not college students from these four societies are immersed in their own culture in a similar fashion or not and to what extent we can say they are (or act as) citizens of the world as some researchers are prompt to call them.

\subsection{Methods}

Our data on the political participation of college students in the public sphere is based on a survey built around three dimensions: 1) the life context (personal, social, cultural and technical resources available to the individual); 2) the media and Internet practices to achieve different goals in three different spheres of life (personal, academic/ professional and public); 3) the personal meanings attributed by students to their own practices. The personal sphere includes practices in the private domain such as health matters, affective needs and relationships with friends. The professional sphere refers to academic training as well as work related uses of Internet. The public sphere concerns the individual's participation in cultural and political life at the local, national and international levels. The survey questions related to the public sphere explore how young adults use media and the Internet to stay abreast of political events, to get involved in political issues and to communicate with others about these issues. Our survey also explores the evaluative dimension of the Internet from the students' point of view. For instance, we asked them to what extent they value the Internet as a means to be better informed and more easily involved in the public spheres and explored their views on the democratic potential of Internet for society. In this article, we will concentrate solely on practices related to the public sphere while taking advantage of our tri-dimensional model. Indeed, we will take into account correlations between, on the one hand, these practices and variables from the life context such as gender and culture, and on the other, between these practices and the personal meanings ascribed to them by the respondents. In other words, this paper presents specific data collected to better apprehend political participation but does not draw on the entire survey, the latter covering a wide range of Internet and media practices.

In total, 4637 questionnaires were distributed in the four countries: 957 questionnaires were handed out in Quebec (Canada); 1350 questionnaires were handed out or filled online in France; 1451 questionnaires were handed out in Mexico and 879 questionnaires were filled out online in Sweden. As may be seen in Table 1, more women than men filled out the survey except in Mexico where the proportions are similar. A vast majority of students in each country were between the ages of 18 and 24 years old except in Sweden where more students over 24 years old completed the questionnaire. Somewhat more students from the social sciences answered the questionnaire in Quebec and in France 
compared to Mexico where the number of respondents in each field of study (Arts and letters, Social sciences, Sciences and math and Professional programs) is comparable. Compared to the other three partners, Sweden has more students from the professional programs and fewer from Arts and letters.

\subsection{Results}

We will examine some of the results of this international survey to explore to what extent young educated adults from different countries avail themselves of the new possibilities created by the Internet to participate in the public sphere. The presentation of this data is organized around two main ideas, that of active and passive participation, and that of positive and negative representations of the Internet. Throughout, we will point out cultural differences and attempt to understand them.

\subsubsection{ACTIVE VERSUS PASSIVE PARTICIPATION}

The Internet now provides easy access to the online version of traditional media as well as to alternative media and a host of other informative sources such as blogs and so on. Given the diversity of resources available, to what extent is the Internet used a source of information for the specific purpose of engagement in the public sphere? In this matter, the Quebec students stand out since $72 \%$ of them turn to the Internet as a source of information on political issues, compared to $46 \%, 40 \%$ and $39 \%$ of their French, Swedish and Mexican counterparts respectively. This is not to say that students in these three countries are less interested in politics, but that, somewhat surprisingly, they count on the Internet to a much lesser degree to help them understand political issues. In the case of the Mexican students, access may be part of the explanation since only $29 \%$ of them have an Internet connection at home (Gobierno de México, 2010) and there is a well-established habit among Mexican youth to follow the news on television since $78 \%$ of them reported doing so in a survey a few years ago (Flores Davila, 2004). In the case of the French and Swedish students, it appears to be not so much a question of access but possibly a stronger habit of consulting newspapers as well as a preference for social activities on the Internet. Whatever the level of use of Internet for the purpose of obtaining political information, and whatever the country, men use it more than women to that end. More importantly, students who are engaged in student life (i.e., holding some responsibility) are also significantly much more likely to use the Internet for that purpose. Even students who simply participate in student life take advantage of the Internet to that end more than their peers who do not. In other words, with regard to the use of the Internet to understand political issues, there is much variability both across and within countries, based on gender and involvement in campus life.

Although a fair number of studies explore young people's Internet practices as we have done, much scarcer are the ones concerned with what they think about the media. As we just saw, young adults do go online, to a certain extent, to collect information on political issues, but how do they evaluate this information? One of the strengths of our 
comparative survey is to take into account the representations as well as the practices. For instance, we found out that the majority of Quebec students $(60 \%)$ were satisfied with the Internet as a source of political information as were the Swedish students (55\%), although their Mexican and French peers were a little less enthusiastic ( $42 \%$ and $39 \%$ respectively). Given that these are rather weak majorities in the best of cases, an interesting issue to explore in subsequent qualitative studies would be the meaning of these reservations.

Given the popularity of video sharing sites such as YouTube (and given that this is a feature specific to the Internet), we wondered if students were interested in viewing videos of a political nature. They only are to a very small extent. The data reveal that only a little over a quarter of the Quebec students (27\%) and a little less of the French students $(22 \%)$ view online videos on political issues. Interestingly, in both countries, men do so more than women as well as students in Arts and letters programs compared to their peers in other fields of study. However, only a meagre handful of the students surveyed actually post political videos online.

When asked whether they had a personal space of any kind on the Internet, the proportion of those who did varied enormously from one country to the next. What was striking however was that only a mere handful used it for political ends, whatever the cultural context. Although the use of social media has skyrocketed since the time of our data collection, the fundamental question remains as to whether the proportion of political uses has increased significantly. Given that it was at such an insignificant level a few years ago, we doubt that the situation would have changed drastically.

As far as taking advantage of the Internet to participate in public debates goes, it was not a well-established practice among the student population surveyed. Although $37 \%$ of the Swedish respondents availed themselves of the Internet for that purpose, very few of their peers from France and Mexico (both 22\%) or Quebec (15\%) did so. This continental divide is also reflected in the results obtained by Calenda and Meijer's (2009) survey among university students in Italy, Spain and the Netherlands (33\%) and those from Ogan, Ozaka and Groshek's (2008) survey with American students (13\%). However, in both these studies, the researchers suggest there might be a bias towards more active students since the survey was conducted online; because this was also the case for the Swedish data in our study, some reservation is in order. The authors also remind us that young people are no longer members of political parties and are not involved in formal political debates but rather participate in single issue movements and networks. It may be that the students in our study interpreted the question as referring to political debates involving traditional parties, which could explain in part the low level of involvement.

Once again, our results showed that, in general, men tend to engage in public debates more often than women do and to be more satisfied with their practices as well. Interestingly, this was also the case in Calenda and Meijer's (2009: 888) study, with the exception of online awareness campaigns and surveys which attracted higher participation from women, "which might confirm that females are more likely to be committed with ethical issues and NGOs than with traditional politics and traditional political organizations". Stromer-Galley and Wichowski (2011) also observe that online forums rarely deal 
with issues important to women (i.e., health, day-care, etc.) and that women dislike the aggressive tone of some exchanges in addition to being the target of unwanted sexual attention in some cases. Given that female respondents form the greater part of the sample in all four countries, the reported low level of participation in public debates in the study as a whole comes as no surprise. As expected, students engaged in student life also used the Internet for public debates more than the others, at least in Quebec. Such observations temper the enthusiasm about the Internet creating a new agora but also raise questions about what motivates students to engage in public debate online and what deters them from doing so.

Should this tendency for respondents to consume information to a much greater extent than creating it be considered as a fragility in the sense that the Internet is not used to its full potential for civic engagement? Stromer-Galley and Wichowski (2011) propose a more nuanced explanation for this lack of active participation. First, they remind us that many offline political events are set up for a few to speak and many to listen and suggest that those who only read comments in online forums may be benefiting from exposure to different points of view and possibly transposing this to offline interactions around political issues. These are interesting questions to follow up in subsequent studies.

Since one of the major advantages of the Internet is to break through geographical barriers (Farthing, 2010), to what extent do students take advantage of this feature for political purposes? Close to half the students in Quebec and Mexico communicate with people in their own country about political issues (and cultural events as well) and only a handful take advantage of the Internet to venture out of their geographical frontiers with regard to such matters. For instance, close to half of Quebec students (48\%) said they communicated online for political purposes (40\% in Quebec, $14 \%$ in Canada and USA, $13 \%$ in Europe and $5 \%$ elsewhere). It would be hasty to bemoan students on the fact that they are not more international in their exchanges on political issues since it may be just as important (if not more so in some cases) to first understand one's own society and become concretely involved in its development. However, such data serve to temper the optimism that is often expressed about the "global or transnational citizen" (Marden, 2011; Trenz, 2009). Once again, we observe that more men than women availed themselves of this feature in all the geographical areas. Not surprisingly, more respondents actively engaged in student life communicated with others from all geographical areas for political purposes. Even students who simply participated in student life used Internet to that end more than their peers who did not. Unfortunately, data on this question is not available from the other countries, but we suggest this would be an avenue to include in subsequent surveys. Indeed, there appears to be a strong connection between offline and online political activities (including discussion) as other researchers have observed (Stromer-Galley and Wichowski, 2011; Calenda and Meijer, 2009).

\subsubsection{Positive Versus negative Representations}

When questioned about the democratic potential of the Internet on a broader scale, significant differences emerge between the countries. With regard to the Internet's 
potential to favour freedom of expression, Swedish students are clearly the most optimistic since $80 \%$ think so, followed closely by their Quebec peers, $70 \%$ of whom believe this to be the case. French and Mexican students are somewhat less convinced since $64 \%$ and $60 \%$ of them are of the same opinion. Earlier, we alluded to studies reporting a grater level of cynicism among French students. It may be pointed out also that Mexican students are not overly enthusiastic about participating in the affairs of their society either. Only $40 \%$ of them felt it was possible to truly express one's opinion in their country (Flores Davila, 2004) and more recently, only 30\% felt they had better opportunities than their parents did to participate in its political life (Gobierno de México, 2010). In all four countries, a majority of students also believe that, as an unfortunate consequence of this freedom, the Internet facilitates the diffusion of hateful content (Sweden 77\%, Quebec $73 \%$, France $63 \%$ and Mexico 56\%). In other words, they basically agree that the potential for participation is there, possibly to use when they feel the need to, while at the same time acknowledging the paradox inherent in this freedom of expression. In spite of the variation between countries, these statements garner the highest rate of approval overall since the respondents are much more divided on other issues, as may be seen in Table 2.

For instance, Swedish students are the most confident that the Internet helps empower ordinary citizens because $60 \%$ of them believe that to be the case while only $33 \%$ of their Quebec and $24 \%$ of their French peers are of that opinion. As to whether the Internet favours greater accountability from public and financial institutions, the Swedish students remain the most optimistic, although more reserved, since $50 \%$ of them believe so, followed closely by their Mexican counterparts (43\%). The response of the latter is not surprising since $57 \%$ of Mexican youth admitted not trusting politicians nor other citizens (Flores Davila, 2004). However, their peers in Quebec and France are decidedly more dubious since only $33 \%$ and $21 \%$, respectively, agree with them. It may be that Swedish students have witnessed more positive examples of dialogue between authorities and citizens. For example, Miegel and Olsson (2012) describe the case of a successful online youth council in a Swedish city. But there may be other cultural differences at play. In a qualitative study with Swedish youth between 18 and 30 years old, Kugelberg (2000) found that university students were generally positive in their life outlook; they considered being in a period of personal freedom that allowed them to gain experience, knowledge and expertise in preparation for their future success in society. This attitude contrasts greatly with sociological studies of French youth depicted as defiant of authority and pessimistic about their life outlook (Galland, 2009). Although the observation might apply to all young adults nowadays, Cicchelli, Martin and Pugeault-Cicchelli (2007) argue that the life trajectories of French youth are much more individualistic than before and that the multiplicity of choices may actually engender great anxiety. Thus, young adults in societies other than Sweden may feel such a distrust of authority that they do not see the Internet as a sufficient tool to help tip the balance. However, the possibility of a bias towards already active students may be operating, given that the Swedish data was collected online.

To summarize the findings from our international survey, there is great variability from one country to the next in the extent to which the Internet is used as a source of information for political purposes. Respondents are also more or less satisfied with this 
practice although there is a certain variability between countries. Viewing or posting political videos is extremely rare (everywhere). Only a minority of students participate in public debates online but they do so somewhat more in Sweden. In countries where data was available, exchanges about political issues take place within the country for the most part.

Overall, students have important reservations about the democratic potential of Internet, revealing that they do not blindly embrace technology, as some writers imply. It is here that the cultural differences are most apparent, with the greatest contrast occurring between France, standing out as the most pessimistic, and Sweden as the most optimistic. A strong sociological trend is the gender difference, with men being almost systematically more interested and more active with regard to politics online. However, an even more significant variable is participation in campus life, confirming that online political activities are intertwined with real-life engagement. Next, we shall discuss the significance of these results from our survey in relation to the conceptualization of the public sphere, while drawing simultaneously from other studies.

\section{TOWARDS A RECONFIGURATION OF tHE TRADITIONAL PUBLIC SPHERE}

The notion of public sphere ${ }^{2}$ has been the object of multiple debates among researchers striving to clarify its meaning. If the concept of public sphere as described by Jürgen Habermas remains the major focal point from which authors have often developed their own perspective, many roads have been travelled since then, even more so since the advent of the digital public spheres. Let's briefly review the main debates attempting to circumscribe the notion of public sphere.

For Habermas (1989), the public sphere is conceived as a foundation for democracy, guided by the idea of common good, where political debates take place in order to arrive at a consensus through rational-critical discussion. It is "[a] domain of our social life where such a thing as public opinion can be formed [where] citizens... deal with matters of general interest without being subject to coercion... [to] express and publicize theirs views (Habermas, 1997: 105, in McKee, 2005: 4). Thus, for Habermas, the notion of public sphere is underpinned by liberal values and discussion in the public sphere should be embedded in communicative rationality, rather than in strategic/instrumental rationality, in order to achieve mutual understanding.

However, different authors have criticized this conceptualization of the notion of public sphere. Following Dacheux (2008), these objections could be summed up in four points: the supposed rationality of the public sphere, its presumed uniqueness, as well as the distinction between the public and the private dimensions and the assumption that participants are equal. For each of the arguments, we will try to see how the practices regarding online political participation and their evaluation by young adults allows us to

\footnotetext{
${ }^{2}$ If some authors are using public sphere in the singular, like Habermas, to talk about one universalistic space for deliberation, others also use it while recognizing the multiplicity of publics within it instead of talking about a multiplicity of public spheres in the plural like others do. This explains why we sometimes put the ' $s$ ' in parenthesis to underscore the idea of "multiplicity".
} 
confirm or partly reject the ideas defended. It goes without saying that this will serve as a preliminary and exploratory reflection on the transformation of the notion of public sphere as our results are not representative of the whole population nor of young adults as such.

First, Habermas' notion of the public sphere should take into account the fact that a person's ability and willingness to be rational at all times is not guaranteed, meaning that the possibility of achieving consensus through rational communication is thwarted with difficulties. In fact, the expectation of rational deliberation in the Habermasian public sphere appears difficult to meet. The French sociologist Loncle (2007) points out that the contemporary individual, freed from the prior normative constraints of group belongings (i.e., church, class, etc.), is faced with the responsibility of creating his own perspective on life and how to conduct himself in society. That can turn out to be a daunting challenge even among the most educated. Social pressures, political strategies, personal ambitions and emotions all converge to influence the way people act in the public sphere. For instance, Miège (2010) defends an interesting thesis when he states that emotions and experiences are more and more often used as justifications to intervene in the public sphere. This enables the multiplication of debate situations, especially through the media, and the emergence of new actors such as "regular citizens" and the "citizen prompt to criticism" that disrupt the legitimacy of those who are officially allowed to talk. In short, according to Miège (2010), there is a displacement from rhetoric to lived experiences. In that same vein, Stromer-Galley and Wichowski (2011: 168) paint a realistic, if not discouraging, picture of online deliberations as being fraught with emotions: "Online discussion is often far removed from the lofty ideals of the Habermasian public sphere; comments may be hastily written, irrational, poorly argued, vested in personal interests, and aimed at attacking the other side". The results from our own survey are in accordance with Stromer-Gally and Wichowski (2011) since in all four sites, a majority of students (from $56 \%$ to $77 \%$ depending on the country) agreed that Internet facilitates the diffusion of heinous content. It then seems that, in agreement with Miège (2010), students are (implicitly) stating that participation in the public sphere is not always a rational activity as individuals' emotions often override logical analysis.

Second, the idea of a unique "bourgeois" public sphere (deliberative and with a universal vocation) is problematic. Indeed, some authors (Fraser, 1992; Hauser, 1998; Fenton, 2010) argue for the multiplicity of public spheres in their own terms (subaltern public spheres, counter public-spheres, etc.). For example, Fraser (1992), in Rethinking the Public Sphere, believes that marginalized people are forming their own public spheres because of their exclusion from the universal public sphere as defined by Habermas. For Fraser (1992, in Frenette and Vermette, 2011: 74), there are "subaltern counterpublics in parallel discursive arenas that fight against the dominant or hegemonic discourses in the political realm". Thus, Fraser sees the public sphere as a space for multiple discourses that express interests, identities and needs other than the one of the dominant public sphere. Likewise, Hauser (1998) recognizes the diversity of discourses in the public sphere, although he talks of publics as mostly formed by members of society who are mobilized around specific issues in accordance with their interests. As we saw earlier, 
this trend is typical of young people. This definition of the notion of public sphere by Hauser thus echoes Dacheux's (2008) first two objections: the public sphere is multiple rather than universal and not entirely rational. Contrary to Habermas' conception of the public sphere as geared towards elites, the modern notion of democracy requires massive participation from all members of society, regardless of their education or expertise; this is why the Internet has appeared as such a promising avenue to revive democracy, through its capacity to overcome distances and bring diverse people together, were it not for the caveats we have mentioned.

In our international survey, most students in all countries affirm that Internet allows for a greater freedom of expression. Indeed, it seems that Internet is the medium of choice for young adults who wish to express their own identities, experiences and interests online as their comments are not censored and can be different from the main dominant social discourses surrounding political debates, thus obliquely suggesting the existence of plural public spheres. Indeed, the fact that $80 \%$ of the Swedish young adults surveyed and $70 \%$ of individuals from Quebec agree that Internet allows for freedom of expression compared to $64 \%$ of their Mexican and $60 \%$ of their French counterparts in itself proves that different opinions can be expressed about the digital public sphere. Hence the idea of a single public sphere as originally proposed is not at all viable and the Internet only serves to accentuate that reality, as an infinite number of interest groups proliferate on the web. In that light, it is not surprising that only a minority of our respondents reported participating in public debates understood in the sense of a broad collectivity.

The third criticism concerns the supposed existence of a clear separation between private life and the public sphere and between the public sphere and the State. Dacheux (2008) shows the blurred frontiers between the two notions by demonstrating that civil societies, States, public sphere(s) and private lives all inter-influence each other's functioning. Hence some private matters can become public affairs. Cardon (2010) gives an example of permeable frontiers between private and public spheres when he shows how professionals, like journalists, come to talk about "fellows" in the media (e.g.: reality TV), making their private life a public matter or when they use politicians' private lives to debate about public affairs. In this arena, young adults have paved the way as they are quite comfortable navigating between the public and private spheres, indeed acting simultaneously in both.

If Habermas conceived of the private and public spheres as two distinct identities, for years now, the proliferation of mass media, sensationalist journalism and so forth have rendered that distinction more obsolete. In fact, we think that Internet has simply exacerbated this tendency. Public and private spheres are harder to distinguish since private life has become meshed with public engagement. Indeed, Loncle (2007) observes that political engagement, from young people's vantage point, often implies acting in one's own name, as a way to foster personal development and pave the way for career opportunities. In addition, it seems that women's personal concerns are directly linked to the participation in the public sphere. As stated earlier, Stromer-Galley and Wichowski (2011) have observed that online forums rarely deal with issues important to women 
(i.e., health, day-care, etc.), and that these tend to be related to public issues that directly impact personal life.

The fourth and final objection relates to the characteristics of the public as being composed of equal individuals debating together for the public good. Indeed, for Fraser (1992), equality is an illusion as not all citizens have similar access to the public sphere(s). As shown by Dacheux (2010), citizens are not all directly connected to the public sphere(s) given that they often rely on mediating agents (i.e., associations, NGOs, family, media, etc.). Nonetheless, there exists a digital divide even within the most affluent societies, as suggested at the beginning of this paper. Finally, Habermas' conceptualization of the public sphere, resting upon the liberal values of liberty and rights, poses the problem of the willingness of the individual to participate in public debates. Indeed, we observed that, even within the privileged segment of the population made up of university students, participation in such debates was very modest.

If students from our comparative study tend to agree that Internet allows freedom of expression, they are not as certain that it has the effect of empowering citizens nor of favouring the transparency of political or financial institutions, thus counterbalancing the idea of the new "powerful regular citizen". It would appear then that equality is more of a hope than a reality as far as participation through the Internet is concerned. Instead, basic socialisation seems be the key. For example, in a country such as Australia where access is not an issue, Yeung, Passmore and Packer (2012) conclude that young adults' social contexts are important socialising agents that promote citizenship participation. Vromen (2007) adds that, while it may be said that the Internet is no panacea, it does, however, encourage the participation of already politically engaged young people by facilitating information sharing and organizing. Our results are in accordance with this observation. In fact, we observe that, even if both men and women have equal access to ICTs in the four countries studied, men are more prone to engage politically than women, thus reiterating already fashioned social patterns and received ideas about politics and leading to a revival of debates about equality between men and women in this regard.

From these four criticisms of Habermas' notion of the public sphere and the discussion of our empirical data in conjunction with the results of other studies, we arrive at a new definition of the public sphere(s) that takes into account the multiplicity of "spheres" catering to different groups (depending on specific issues or identities, interests and so on) that co-exist and interact with the dominant group. As Bennett (2008: 13, in Frenette and Vermette, 2011: 75) states, it is primordial to have a broad vision of the public sphere following the recent generational shift in post-industrial democracies from self identity related to traditional politics and culture (strong groups such as labour, class, party) to the network society where individuals participate in loosely tied associational chains and are more responsible for the production and management of their own social and political identities". In other words, citizens are more likely to bypass traditional authoritarian avenues in order to engage in the public sphere as a way to affirm their own identities in relation with their personal values and young educated adults appear to be at the forefront of these significant social transformations. 


\section{CONCLUSION}

In what ways can we say that the Internet is related to changes in the public sphere? We have come to the conclusion that the reconfiguration of the public sphere, as originally conceived by Habermas, is driven by deep-seated social changes and these changes are supported, and in some cases heightened, by Internet practices. Deliberations in the public sphere have rarely, if ever, been driven exclusively by rationality and a concern for the common good. But the anonymity of the Internet, coupled with its availability, make it easier than ever to let personal issues dominate public discourse. In the same manner, post-modern society has witnessed the proliferation of self-interest groups but the Internet allows them to thrive easily, leading to an unprecedented proliferation of multiple "public" spheres. The predominance of individual trajectories with regard to life outlook and one's role in society favours the intermingling of personal interests with matters that concern society as a whole; once again, the Internet offers the possibility of publicizing and defending one's private issues to a broad audience. Finally, citizens have never been on a totally equal footing with regard to power structures; although on this point, the Internet has allowed a much larger number of people to intervene in ongoing public discourses, people do not have the same abilities, whether technical or social, to avail themselves of these possibilities. In concluding, we want to underline the fact that much research remains to be done and we would like to share four insights as to how the topic of young adults' involvement in the public sphere should be conceptualized and to make a few suggestions with regard to issues that need further studies.

First and foremost, we would like to underscore the importance of culture in relation to political practices on the Internet. The international comparison of our data allows us to observe important variations in how the respondents engage in the public sphere from one country to the next. This observation stresses the importance of contextualisation when it comes to understanding the Internet practices of young adults in the digital public sphere. Therefore, it is misleading to assume that young people have universal practices, as several authors seem to imply. Practices vary greatly not only between college students within the same university but also between regions of the world. Our data show that there are significant variations between societies as to how satisfied they are with their own practices and how they view the social role of Internet.

Second, we think it is misleading to conceive of political engagement as an all or none issue. Although the Internet allows astonishing opportunities for individuals to participate in the public sphere, it does not mean that college students constantly and fully exploit the potential of this media. In other words, it is not because the advantages of the Internet to engage in the public sphere are significant (i.e. communicate with people around the world, organize protests, obtain political information, etc.), that college students will necessarily avail themselves of these opportunities on a permanent basis. As Gripsrud (2009) points out, involvement in the public sphere is always an option that can be actualized when the need is felt. In addition, Jouët (2009) suggests that there are varying degrees of public involvement, from permanent activism to fleeting interest. Our data suggest that the first kind remains a minority. Since overall, students in our survey 
are more often observers of the public sphere than active participants, the important question then becomes why they choose this stance. It may be that they go online to engage in the public sphere during specific periods or for special causes (i.e., elections, summit meetings, unpopular legislation, armed conflicts, etc.).

Third, we wish to stress, along with other authors we have quoted throughout this paper, that the dissociation of on-line and off-line political practices is not a fruitful avenue for research. Indeed, in concordance with the results of other studies such as Hirzalla and van Zoonen (2011), our survey data revealed that the use of Internet for political purposes are more characteristic of college students who are already involved in student life. It seems imperative, from now on, to consider that the on-line and off-line modes of political participation are meshed together. A fourth and final insight we wish to share regards mental representations of the digital public sphere. Although students in the four countries vary with respect to their level of optimism or scepticism, on the whole, they tend to be dubious with regard to its potential to empower ordinary citizens or to encourage transparency from financial and political organisations. Low levels of participation in public debates, then, come as no surprise. Therefore, when analyzing Internet practices and speculating about the potential of Internet, we think it is important to take into account young adults' viewpoints on the matter in order to achieve a better understanding of their practices.

Among the issues we consider important for subsequent studies, the persistent differences between young educated men and women with regard to political engagement on the whole and political practices online merit our full attention. Indeed, it seems that the traditional roles of men and women associated with the public and private spheres still permeate some aspects of social life. Some researchers such as Gavray, Born and Waxweiler (2012) have conducted extensive studies showing how socialisation practices subtly orient young men and women towards different conceptualizations of their role in the public sphere. It then appears that, if the digital public sphere is to fulfill its potential to transform political engagement by allowing everyone who has access to ICTs to participate in political debates, accessibility to these media is not enough to transcend previously anchored states of mind and practices. Our prior point about the importance of taking into account social representations relative to political engagement thereby takes on additional relevance.

In the coming years, it will also be especially interesting to continue exploring how the dynamics of the public sphere are being once again challenged by the popularity of such communication technologies as Facebook and Twitter. Nonetheless, ICTs such as the Internet, no matter how sophisticated they become, will not in and of themselves transform young adults' involvement in the public sphere unless they feel strongly motivated to do so. However, those hoping for greater political involvement from the new generations could harness their potential and attempt to reach young adults in ways that speak to their concerns and values. Some promising projects and studies have already been undertaken in this regard and offer some useful insights. For instance, Wells (2010) and Freelon (2011) reviewed online civic engagement websites for youth and both stress 
the importance of designing open-ended forums where young people would feel free to express themselves on a wide variety of issues. The design and evaluation of such initiatives are equally important goals for future research and hopefully, a subsequent follow-up to our survey would eventually reveal a greater involvement of young adults in the public sphere.

\section{REFERENCES}

Arnett, J.J. (2004) Emerging adulthood. The winding road from the late teens through the twenties, New York: Oxford University Press.

Bastien, F.C. (2004) 'Branchés, informés et engagés? Les Canadiens, Internet et l'élection fédérale de 2000', Politique et Sociétés, 23 (1): 171-191.

Beck, U. (2001) 'Freedom's children' in Beck, U. and Beck-Gensheim, E. (eds.) (2001) Individualisation, London: Sage, pp. 156-71.

Beck, U. (1992) Risk society. Towards a new modernity, London: Sage.

Bélanger, É. and Nadeau, R. (2009) Le comportement électoral des Québécois, Montréal: Presses de l'Université de Montréal.

Bennett, W. L. (2008) 'Changing citizenship in the digital age' in Bennett, W. L. (ed.) (2008) Civic life online: Learning how digital media can engage youth, Cambridge, MA: MIT Press, pp. 1-25.

Blais, A. (2008) 'Mon vote peut-il faire la difference?' in Les professeurs de science politique de l'Université de Montréal (eds.) (2008) La politique en questions, Montréal: Presses de l'Université de Montréal, pp. 53-7.

Britt, T.W. (2003) 'Motivational and emotional consequences of self-engagement: Voting in the 2000 U.S. presidential election', Motivation and Emotion, 27 (4):339-58.

Calenda, D. and Meijer, A. (2009) 'Young people, the Internet and political participation. Findings of a web survey in Italy, Spain and The Netherlands', Information, Communication and Society, 12 (6): 879-98.

Cardon, D. (2010) La démocratie Internet. Promesses et limites, France: Éditions du Seuil et La République des Idées.

Caron, A.H. and Caronia, L. (2005) Culture mobile: Les nouvelles pratiques de communication, Montréal: Presses universitaires de Montréal.

Cicchelli, V., Martin, C. and Pugeault-Cicchelli, C. (2007) 'Les jeunes adultes en France : un débat politique et scientifique' in Loncle, P. (ed.) (2007) Les jeunes, Questions de société, questions de politique, Paris : La documentation française, pp. 25-44.

Dacheux, É. (2008) 'L'espace public: un concept clef de la démocratie' in Dacheux, É. (ed.) (2008) L'espace public, Paris: CNRS Editions, pp. 8-17.

Dahlgren, P. (2012) 'Web et participation politique: Quelles promesses et quels pièges?' Questions de communication, 21: 13-24. 
Dahlgren, P. (2008) 'L'espace public et les médias: une nouvelle ère ?' in Dacheux, É. (ed.) (2008) L'espace public, Paris: CNRS Éditions, pp. 61-83.

Farthing, R. (2010) 'The politics of youthful antipolitics: representing the 'issue' of youth participation in politics', Journal of Youth Studies, 13 (2): 181-95.

Fraser, N. (1992) 'Rethinking the public sphere: A contribution to the critique of actually existing democracy' in Calhoun, C. (ed.) (1992) Habermas and the public sphere, Cambridge, MA: MIT Press, pp. 109-42.

Fenton, N. (2010) 'Re-imagining democracy. Mew media, young people, participation and politics' in Olsson, T. and Dahlgren, P. (eds.) (2010) Young people, ICTs and democracy. Theories, policies, identities and websites, Sweden: Nordicom, pp. 19-34.

Flores Davila, J.I. (2004). 'Paris gagnés, paris perdus : valeurs et croyances chez les jeunes' in Perez Islas, J. A. and Valdez Gonzalez, M. (eds.) (2004) Regard sur... la jeunesse au Mexique, Québec : Éditions de l'IQRC, pp. 187-206.

Frenette, M. and Vermette, M.F. (2011) 'Young adults'involvement in the public sphere : A comparative international study' in Correia, J.C. and Rousiley, M.C. (eds.) (2011) The Public Sphere Reconsidered: Theories and Practices, Portugal: LabCom books, pp. 73-90.

Furlong, A. and Cartmel, F. (2007) Young people and social change: individualisation and risk in late modernity, 2d ed., Maidenhead: Open University Press.

Galland, O. (2009) Les jeunes, Paris: La Découverte.

Gavray, C., Born, M. and Waxweiler, C. (2012) 'La dimension du genre dans l'étude de la participation sociale, civique et politique' in Fournier, B. and Hudon, R. (eds) (2012) Engagements citoyens et politiques de jeunes. Bilans et expériences au Canada et en Europe, Québec: Presses de l'Université Laval, pp. 65-79.

Giddens, A. (1991) Modernity and self-identity: Self and society in the late modern age, Cambridge: Polity Press.

Gobierno de México (2010) Encuesta national de juventud. http://bdsocial.inmujeres.gob.mx/index.php/ enjuve-38/encuesta-nacional-de-juventud

Gripsrud, J. (2009) 'Digitising the public sphere: Two key issues', Javnost - The Public, 16 (1): 5-16.

Habermas, J. (1989) (German 1962) The structural transformation of the public sphere: An inquiry into a category of bourgeois society, Cambridge, MA: MIT Press.

Hauser, G. (1998) 'Vernacular dialogue and the rhetoricality of public opinion', Communication monographs, 65 (2): 83-107.

Imjuve (Instituto Mexicano de la Juventud) and UNA (Universidad Nacional Autonoma de México) (2012) Encuesta national de valores en juventud http://www.juridicas.unam.mx/invest/areas/opinion/envaj/ resultados.htm

Jouët, J. (2009) 'The Internet as a new civic form. The hybridisation of popular and civic Web uses in France', Javnost - The Public, 16 (1): 59-72.

Kugelberg, C. (2000) 'Young Adult Life With and Without Limits. Different Discourses Around Becoming Adult Among Swedish Young People', Young. Nordic Journal of Youth Research, 8 (1): 36-53.

Livingstone, S., Bober, M. and Helsper, E. (2004) Active participation or just more information?, London: London School of Economics. 
Loncle, P. (2007) 'Jeunes et politique : amours et désamours' in Loncle, P. (ed.) (2007) Les jeunes, Questions de société, questions de politique, Paris : La documentation française, pp. 101-128.

Marden, P. (2011) 'The digitised public sphere: Re-defining democratic cultures or phantasmagoria?', Javnost - The Public , 18 (1): 5-20.

McKee, A. (2005) The public sphere: an introduction, Cambridge: Cambridge University Press.

Miège, B. (2010) L'espace public contemporain. Approche info-communicationnelle, Grenoble: Presses de l'Université de Grenoble.

Miegel, F. and Olsson, T. (2012) 'A generational thing? The internet and new forms of social intercourse', Continuum: Journal of Media and Cultural Studies, 26 (3): 487-99.

Milner, H. (2007) 'La connaissance et la participation politiques des jeunes Américains, Canadiens et Québécois' in Venne, M. and Fahmy, M. (eds.) (2007) L'annuaire du Québec 2008, Montréal : Fides, pp. 85-95.

Mindich, D. T. Z. (2005) Tuned Out. Why Americans Under 40 Don't Follow the News, Oxford: Oxford University Press.

Niemi, R. G. and Weisberg, H. F. (eds) (2001) Controversies in Voting Behavior, Washington, DC: CQ Press.

Norris, P. (2003), Young people and political activism: from the politics of loyalty to the politics of choice [Www. pippanorris.com, accessed 11/01/2008].

Ogan, CL., Ozaka, M. and Groshek, J. (2008) 'Embedding the Internet in the lives of college students. Online and Offline behaviour', Social Science Computer Review, 26 (2): 170-7.

Pammett, J.H. and Leduc, L. (2005) Pourquoi la participation décline aux élections fédérales canadiennes: un nouveau sondage des non-votants, Ottawa: Élections Canada.

Pattie, C., Seyd, P.A. and Whiteley, P. (2004) Citizenship, democracy and participation in contemporary Britain, Cambridge: Cambridge University Press.

Sarra-Bournet, B. (2008) La démocratie de l'asbsention, Reseach Report [www.crp.uquam.ca/pages/docs/ centres/cm/Bruno\%20Sarra-Bournet.pdf, accessed 03/01/2013]

Stockemer, D. (2012) 'Students' political engagement: a comprehensive study of University of Ottawa undergraduate students', Journal of Youth Studies, 15 (8): 1028-47.

Stromer-Galley, J. and Wichowski, A. (2011) 'Political discussion online' in Consalvo, M. and Bucht, C. (eds.) (2011) Handbook of Internet studies, Malden, MA: Wiley-Blackwell, pp. 168-87.

Theocharis, Y. (2011) 'Young people, political participation and online postmaterialism in Greece', New Media and Society, $13(2): 203-23$.

Trenz, H.-J. (2009) 'Digital media and the return of the representative public sphere', Javnost - The Public, 16 (1): $33-46$.

Vromen, A. (2007) 'Australian young people's participatory practices and Internet use', Information, communication and society, 10 (1): 48-68.

Wells, S.D. and Dudash, E.A. (2007) 'Wha'd'ya know? Examining young voters' political information and efficacy in the 2004 election', American Behavorial Scientist, 50 (9): 1280-89. 
Wolton, D. (2008) 'Les contradictions de l'espace public médiatisé' in Dacheux, É. (ed.) (2008) L'espace public, Paris: CNRS Éditions, pp. 37-59.

Yeung, P., Passmore, A. and Packer, T. (2012) 'Examining citizenship participation in young Australian adults: a structural equation analysis', Journal of Youth Studies, 15 (1) : 73-98.

\section{APPENDIX}

\begin{tabular}{lcccc}
\hline & Quebec & France & Mexico & Sweden \\
\hline Sex & 66 & 68 & 53 & 68 \\
Women & 34 & 32 & 47 & 32 \\
Men & 80 & 96 & 89 & 65 \\
Age & 13 & 4 & 5 & 23 \\
18-24 years old & 7 & - & 6 & 12 \\
$25-30$ years old & & & & \\
Over 30 years old & 39 & 46 & 50 & 51 \\
Field of Study & 42 & 33 & 26 & 24 \\
Arts and Letters & 19 & 21 & 24 & 25 \\
Social Sciences & & & & \\
Sciences and Math & & & & \\
\hline
\end{tabular}

Table 1: Sample characteristics by sex, age and field of study in the four countries (in percentages)

\begin{tabular}{lcccc}
\hline & Sweden & Quebec & France & Mexico \\
\hline Freedom of expression & 80 & 70 & 64 & 60 \\
Diffusion of heinous content & 77 & 73 & 63 & 56 \\
Citizen empowerment & 60 & 33 & 24 & $\mathrm{n} / \mathrm{a}$ \\
Accountability from institutions & 50 & 33 & 21 & 43 \\
\hline
\end{tabular}

Table 2. Total percentage of students in four societies who agree with statements about the potential of the Internet to favour different phenomena 